\title{
Research on improving the accuracy of FDM 3D printing process by using a new designed calibrating part
}

\author{
Răzvan Păcurar ${ }^{1, *}$, Valentin Buzilă ${ }^{1}$, Ancuţa Păcurar $^{1}$, Eugen Guţiu ${ }^{1}$, Sergiu Dan $\operatorname{Stan}^{2, \dagger}$, \\ and Petru Berce ${ }^{1}$ \\ ${ }^{1}$ Department of Manufacturing Engineering, Faculty of Machine Building, Technical University of \\ Cluj-Napoca, B-dul Muncii 103-105, 400641, Cluj-Napoca, Romania \\ ${ }^{2}$ Department of Mechatronics and Machine Dynamics, Faculty of Automotive, Mechatronics and \\ Mechanical Engineering, Technical University of Cluj-Napoca, B-dul Muncii 103-105, 400641, Cluj- \\ Napoca, Romania
}

\begin{abstract}
The article presents theoretical and experimental research methods that were used at the Technical University of Cluj-Napoca (TUCN) to improve the accuracy of Fused Deposition Modeling (FDM) 3D printing process. Finite element analysis method was successfully used for estimating the shrinkages of an original calibrating part that has been originally conceived for this purpose, this part being finally made using an original software application and FDM 3D printing equipment at TUC-N.
\end{abstract}

\section{Introduction}

The accuracy desired of a 3D printed part depends heavily on the design of the part. Variations in cooling and curing will result in big internal stress that can lead to failure, warping or shrinkage [1]. The accuracy also depends on the material used in the printing process [2]. Since there is a small amount of filament types available on the market, such as: ABS, PLA, PET, Nylon, TPU, PC [3] there are several ways to adjust the theoretical values needed in such manner that the printed dimensions will be at the end as close as possible to the desired dimensions designed using CAD programs [4]. Finite element analysis methods and software applications (programs) are successfully used to determine scale factors needed to compensate the shrinkage of the printed parts [5]. Calibrations procedures and calibrating parts need to be used in combination with these methods in order to reach the optimum technological parameters in closed connection with the desired accuracy at the end [6]. The research presented on this article was focused on improving the accuracy of the FDM 3D printing equipment from Technical University of Cluj-Napoca, by analyzing and developing of a calibrating software application and an originally calibrating part that has been conceived for this purpose. Measurements were realized using CMM equipment and dimensions were compared with the theoretical values and polynomial

\footnotetext{
* Corresponding author: Sergiu.Stan@mdm.utcluj.ro

${ }^{\dagger}$ Corresponding author: Razvan.Pacurar@tcm.utcluj.ro
} 
functions were used for the realization of the optimized software application. The results reached using the conceived software application were used in the $3 \mathrm{D}$ printing process of a cogwheel for a photo tripod at the end.

\section{FEA for estimating the shrinkage of calibrating part}

The calibrating part that was originally conceived for calibration of the $3 \mathrm{D}$ printing process is presented in Fig.1. As one may notice, the calibrating part has been conceived as having different types of cylinders and holes, with the diameter varying between 1-20 mm in size.
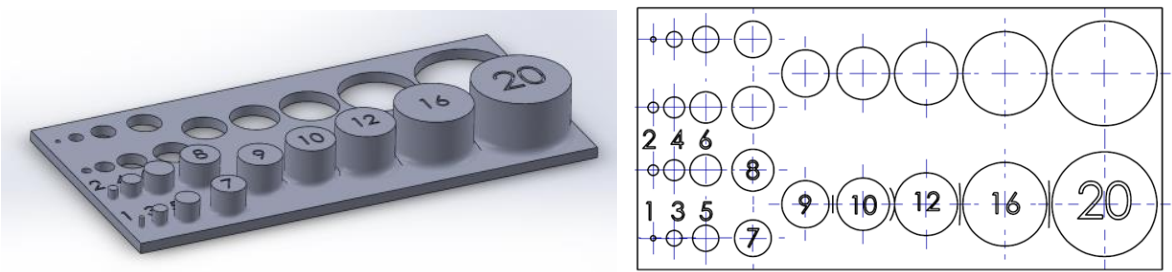

Fig. 1. 3D model and 2D drawing of the calibrating part

SolidWorks Simulation was used for the Finite Element Analysis that was made to estimate the shrinkage of the designed calibrating part. PLA material has been considered, with characteristics defined in the simulation as they were taken from the website of the producer of this type of material for 3D printing process (see Fig.2).

\begin{tabular}{|l|l|l|}
\hline Property & Value & Units \\
\hline Shear Modulus & 318.9 & $\mathrm{~N} / \mathrm{mm}^{\wedge} 2$ \\
\hline Mass Density & 1300 & $\mathrm{~kg} / \mathrm{m}^{\wedge} 3$ \\
\hline Tensile Strength & 37 & $\mathrm{~N} / \mathrm{mm}^{\wedge} 2$ \\
\hline Compressive Strength & & $\mathrm{N} / \mathrm{mm}^{\wedge} 2$ \\
\hline Yield Strength & 35.9 & $\mathrm{~N} / \mathrm{mm}^{\wedge} 2$ \\
\hline Thermal Expansion Coefficient & $4.1 \mathrm{e}-005$ & $/ \mathrm{K}$ \\
\hline Thermal Conductivity & 0.13 & $\mathrm{~W} /(\mathrm{m} \cdot \mathrm{K})$ \\
\hline Specific Heat & 1386 & $\mathrm{~J} /(\mathrm{kg} \cdot \mathrm{K})$ \\
\hline Material Damping Ratio & & $\mathrm{N} / \mathrm{A}$ \\
\hline
\end{tabular}

Fig. 2. Characteristics of the PLA material considered for the FEA analysis [7]

Kinematical and technological constrains were imposed as shown in Fig.3. To find out where and how big the shrinkages are, a difference of -40 degrees $\mathrm{C}$ in the temperature was applied in a static study. The difference of temperature between the temperature of the 3D printers' enclosure and the ambient temperature was applied as an external load. The part had three surfaces as Roller/slider fixtures to simulate the positioning of the calibrating part on the heated bed. Roller/slider fixtures were applied on the base and on two side surfaces to simulate the position on the heated bed.
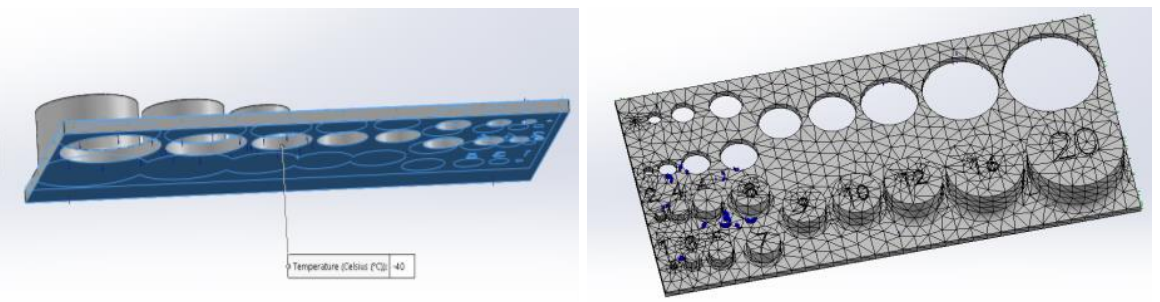

Fig. 3. Constrains imposed in the finite element analysis and mesh that was generated 
After the mesh has been generated, the running of the analysis was possible to be made in order to determine the stresses and displacements resulted in the case of the calibrating part (see Fig.4).
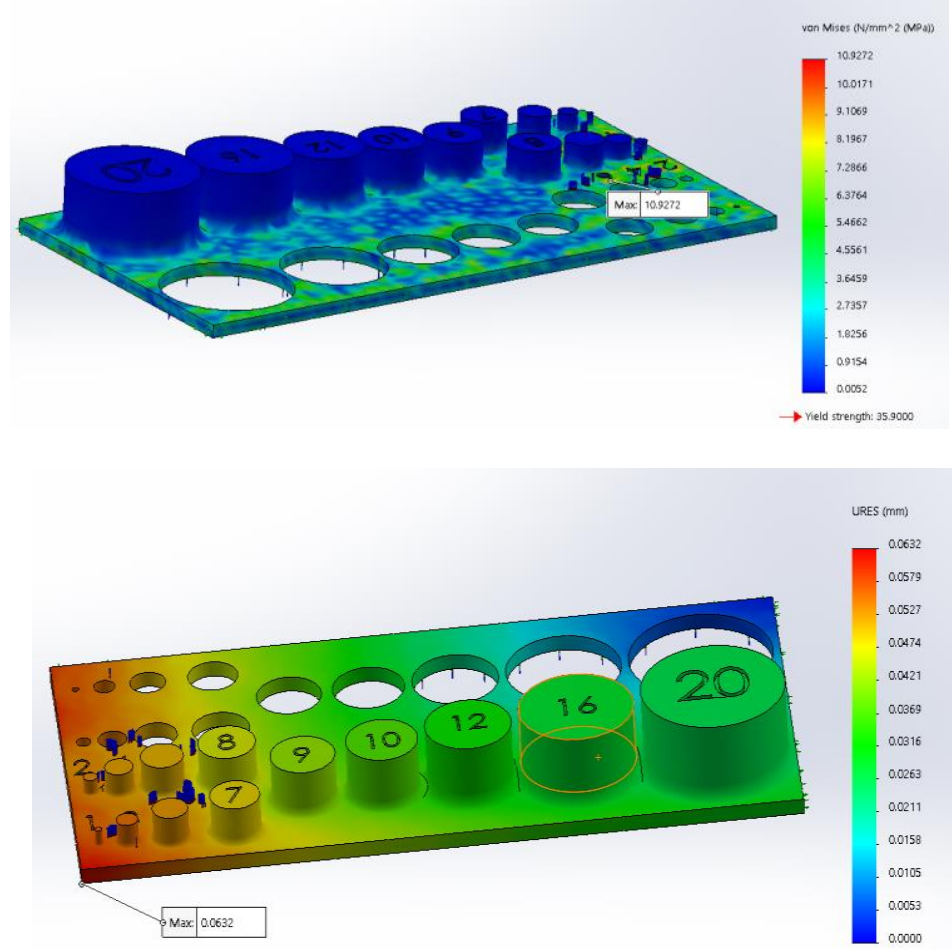

Fig. 4. Von Mises stress and displacement as estimated by finite element analysis

As one may notice in Fig. 4, all the stress caused by the decrease in temperature is in fact internal stress, in the mass of the calibrating part. As regarding the displacements result obtained in the FEA, these displacements are distributed as shown in Fig.4, but, in fact, the displacement can only be measured, but not localized since the calibrating part is not $100 \%$ attached to the printer's bed. The result on the stress is not important to the study, since the stresses are mainly in the mass of the material, as internal stress, the dislocations, even if are not as big as it was initially thought, reaching $0.006 \mathrm{~mm}$ in some areas of the calibrating part. Adding $1 \%$ of $0.6 / 2$ (since the contraction should be theoretically on both ends of the filament) $\mathrm{mm}$ from the contraction of the filament, the result is $0.009 \mathrm{~mm}$. To extrapolate the results, the shrinkages were further on considered in the development of the software application as a function of length which, in addition to the function of practical, measured inaccuracies are added on to a finite result in the application on the form of a global scaling factor for a certain dimension.

\section{3D Printing and measuring of the calibrating part}

For printing the calibrating part that has been designed and analysed as shown, FDM 1650 equipment from Department of Manufacturing Engineering (Technical University of ClujNapoca) was used as shown in Fig.5. 

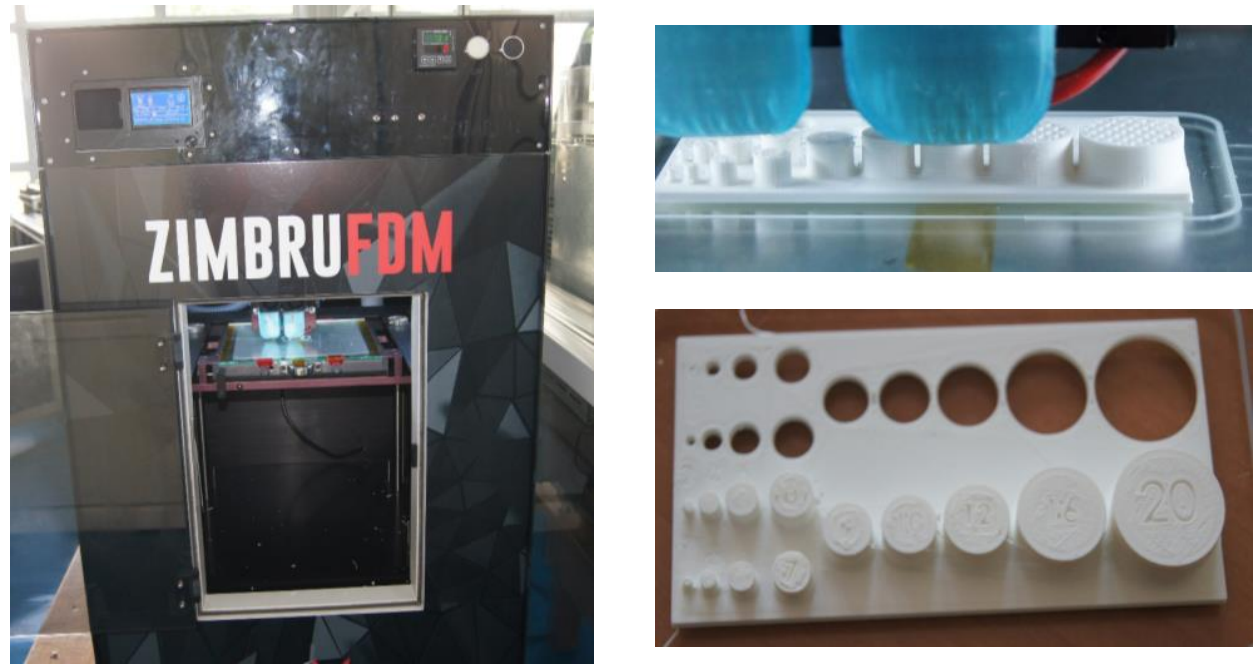

Fig. 5. FDM printer used for the realization of 3D printed calibrating part

The filament used was a white PLA with a diameter of $1.75 \mathrm{~mm}$, using the extruder 1, heated at 205 Celsius degrees, and with the bed heated at 50 Celsius degrees. During the printing, the temperature varied between 190 and 210 Celsius degrees while the table had 45-50 Celsius degrees. The nozzle used was a $0.6 \mathrm{~mm}$ with a $1.75 \mathrm{~mm}$ white PLA material. The inner structure was a $+45 /-45$ degrees as seen in the right top image in Fig.5.
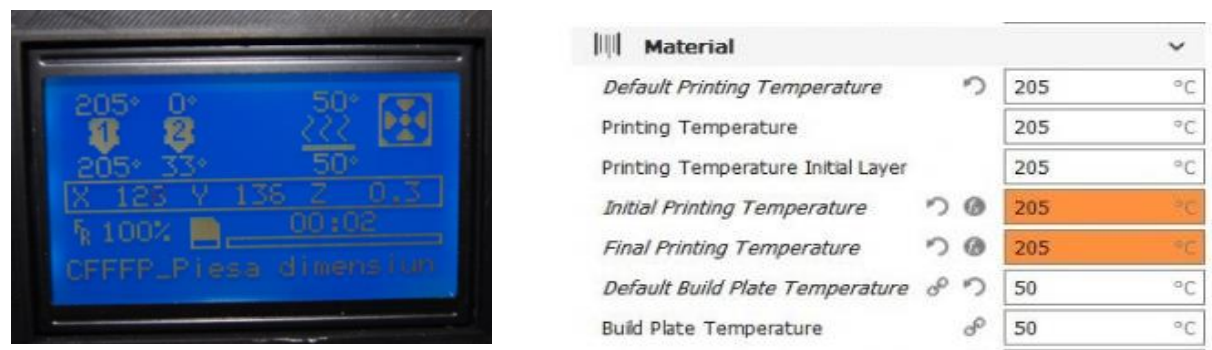

Fig. 6. Technological parameters used for 3D printing process of the calibrating part

The measuring instruments used were two electronic "knife shaped callipers - A type" with $0.01 \mathrm{~mm}$ accuracy according to DIN 862 and one micrometre with $0.01 \mathrm{~mm}$ accuracy as well. An arithmetic media was made for each dimension and, based on the slope of equation resulted from the difference between the theoretical and practical dimension has been determined. In Table 1, Table 2 and graphics shown in Fig.7, the slope of each theoretical to practical dimension is presented, with the function that resulted from each measurement and the R-squared, which is a statistical measure that represents how close the inserted data to the fitted regression line is. The closer to 1 , the better the model fits the data. As one may notice in Fig. 7, in both cases (cylindrical and hole dimensions) are presented the linear regression, the functions and the values of R-squared in both cases are very closed to 1 , which means that the inserted values are very closed to the regression line. The values that were obtained after the measurements that were realized were used to compensate the deviations of the calibrating part, for this purpose a software solution application being originally conceived and developed in this sense. 
Table 1. Arithmetic media of the cylindrical values measured

\begin{tabular}{|l|l|l|l|l|l|l|l|l|l|l|l|l|l|}
\hline $\begin{array}{l}\text { Theoretic } \\
\text { al value } \\
<\mathbf{m m}>\end{array}$ & $\mathbf{2 0}$ & $\mathbf{1 6}$ & $\mathbf{1 2}$ & $\mathbf{1 0}$ & $\mathbf{9}$ & $\mathbf{8}$ & $\mathbf{7}$ & $\mathbf{6}$ & $\mathbf{5}$ & $\mathbf{4}$ & $\mathbf{3}$ & $\mathbf{2}$ & $\mathbf{1}$ \\
$\begin{array}{l}\text { Practical } \\
\text { value } \\
<\mathbf{m m}>\end{array}$ & 19.86 & 15.89 & 11.89 & 9.90 & 8.87 & 7.87 & 6.86 & 5.81 & 4.83 & 3.84 & 2.85 & 1.97 & 1.60 \\
\hline $\begin{array}{l}\text { Differenc } \\
\text { e }<\boldsymbol{\mu m}>\end{array}$ & -134 & -109 & -106 & -99 & -128 & -128 & -135 & -183 & -167 & -158 & -149 & -23 & +600 \\
\hline
\end{tabular}

Table 2. Arithmetic media of the holes values measured

\begin{tabular}{|l|l|l|l|l|l|l|l|l|l|l|l|l|l|}
$\begin{array}{l}\text { Theoretic } \\
\text { al value } \\
<\text { Imm> }\end{array}$ & $\mathbf{2 0}$ & $\mathbf{1 6}$ & $\mathbf{1 2}$ & $\mathbf{1 0}$ & $\mathbf{9}$ & $\mathbf{8}$ & $\mathbf{7}$ & $\mathbf{6}$ & $\mathbf{5}$ & $\mathbf{4}$ & $\mathbf{3}$ & $\mathbf{2}$ & $\mathbf{1}$ \\
\hline $\begin{array}{l}\text { Practical } \\
\text { value } \\
<\mathrm{mm}>\end{array}$ & 19.55 & 15.45 & 11.46 & 9.35 & 8.28 & 7.28 & 6.22 & 5.18 & 4.23 & 3.26 & 2.33 & 1.18 & 1.30 \\
$\begin{array}{l}\text { Difference } \\
<\mu \mathrm{m}>\end{array}$ & -445 & -548 & -533 & -643 & -724 & -721 & -776 & -817 & -765 & -738 & -664 & -815 & -550 \\
\hline
\end{tabular}
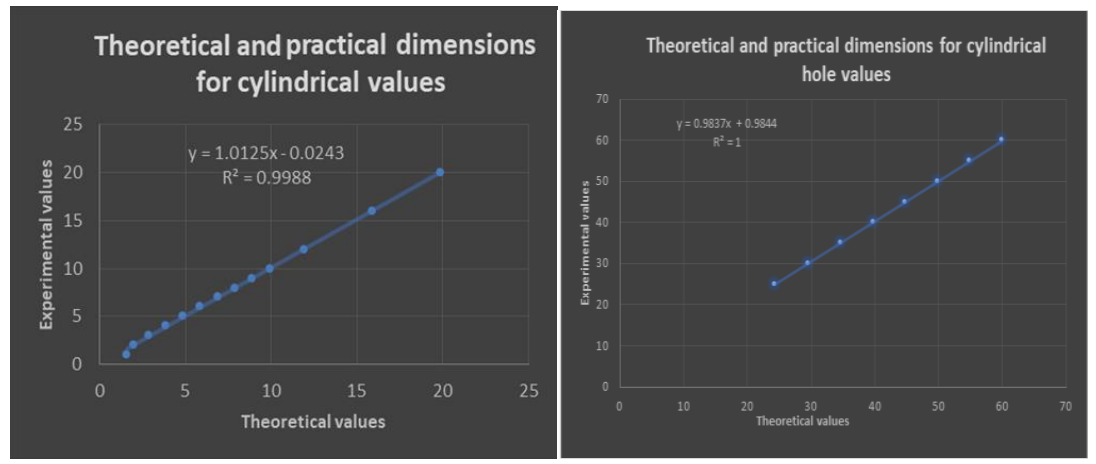

Fig. 7. Measurements of the cylindrical and hole dimensions of the calibrating part

\section{Original software application conceived for better calibrating the 3D printing process}

The hypothesis that has been considered for the software application that was conceived for adjusting the dimensions of the calibrating part was the one that the deviations are approximately linear. To explain better, if there is an offset of $1 \mathrm{~mm}$ in one direction, that can be corrected, but if the inaccuracy comes as a bidirectional, as in the case of a hole, the pitch of the lead-screws cannot be corrected before or while printing, so the calibration should be realized using the printers software or, as a stand-alone application that should correct merely the CAD model. Taking the data obtained in the Table 1 and 2, a function that is similar to the one displayed on the graphics presented in Fig 7 was introduced in a series of linear regression equations. Mathematically, a linear equation is defined by the following equation:

$$
y=b x+a+\varepsilon
$$

where: $\mathrm{x}$ - independent variable and represent the value that needs to be obtained; $\mathrm{y}$ dependent variable, which represent the value to be entered in CAD program; a-Yintercept, which is the expected mean value of $\mathrm{y}$ when all $\mathrm{x}$ variables are equal to 0 . 
On a regression graph, it's the point where the line crosses the $\mathrm{Y}$ axis.

$\mathrm{b}$ - the slope of a regression line, which is the rate of change for $\mathrm{y}$ as $\mathrm{x}$ changes; $\varepsilon$ - the random error term, which is the difference between the actual value of a dependent variable and its predicted value. In the analysed case, this predicted value is given by the thermal shrinkage scaling factor plus global scaling factor. The global scaling factor is obtained using formula:

$$
\varepsilon=1+\frac{\text { Dim }_{\text {real }}-\text { Dim_CAD }_{-}}{\text {Dim_CAD }}
$$

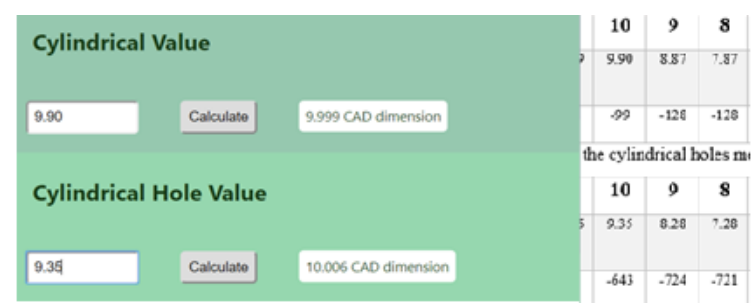

Fig. 8. Original software application used for the calibration of $3 \mathrm{D}$ printing process

\section{Conclusions}

An original calibrating part was conceived for the calibration of the 3D printing process and finite element analysis (FEA) was done to estimate the thermal shrinkages that occur in 3D printing process. The results obtained within FEA were further used for the conceiving of an original software application that optimizes the calibration of the $3 \mathrm{D}$ printing process. Measurements that were realized using the originally conceived calibrating part manufactured by $3 \mathrm{D}$ printing process proved that there were significant improvements in terms of accuracy regarding the FDM 3D printing equipment from the Department of Manufacturing Engineering from the Technical University of Cluj-Napoca, but, since the flow of the material can be unpredictable and all the 3D printers are unique, experimental data should be made on each combination of parameters in the future for calibrating each type of equipment in particular (taking into account the type of materials that are used) for $3 \mathrm{D}$ printing process.

Acknowledgement: This paper was supported by Romanian Ministry of Research and Innovation (UEFISCDI), Project cod PN-III-P1-1.2-PCCDI-2017-0224 (no. 77PCCDI/2018, DigiTech) within PNCDI III programme.

\section{References}

1. T. Nieszporek R. Gołębski, L. Soos Technical Gazette, 24, (2017)

2. C. Borzan- Miron, M. Moldovan; V. Bocanet, Revista de Chimie, 69, 4, (2018)

3. C. Moldovan, C. Cosma, P. Berce, N. Balc, Acta Technica Napocensis, 61, 3, (2018)

4. D. Baila, S. Tonoiu, B. of the Polish Academy of Sciences, Technical S, 67, 3, (2019)

5. J. Milde; L. Morovic; J. Blaha, MATEC Web of Conferences, 137, (2017)

6. N.-M., Ludmila; N.Marcincin, Applied Mechanics and Materials, 309, (2013)

7. Characteristics of PLA material, http://2015.igem.org/wiki/images/2/24/CamJIC-Specs-

Strength.pdf 